\title{
DESIGN AND ANALYSIS OF CRANE HOOK WITH DIFFERENT MATERIAL
}

\section{K. DINESH}

Department of Mechanical Engineering, AMET University, Chennai, Tamil Nadu, India

In this paper the plan of the snare is finished by systematic strategy and configuration is accomplished for the distinctive materials like manufactured steel and high malleable steel. After the expository strategy plan and demonstrating of the snare is done in displaying programming (strong edge). The displaying is finished utilizing the outline figuring from the demonstrating the investigation of the snare is done in FEA programming (ANSYS). This result leads us to the assurance of worry in existing model. By anticipating the anxiety fixation territory, the snare working life increment and diminish the disappointment stretch.
\end{abstract}

KEYWORDS: Crane Hook, Ansys, FEA Programming, Modeling, Meshing \& Stress Analysis.

Received: Oct 05, 2017; Accepted: Oct 24, 2017; Published: Jan 23, 2018; Paper Id.: IJMPERDFEB201882

\section{INTRODUCTION}

Crane snares are very obligated parts and are constantly subjected to disappointment because of accretion of vast calculate of stresses which can result in the long run without delay its collapse. Crane snares are the fragment which is by, and hugely used to lift the overwhelming saddle in ventures and constructional locales. A crane is an apparatus, furnished with a derrick, wire ropes or anchors and stacks used to lift and move overwhelming substance. Cranes are for the most part utilized in transport, [3-6] construction and assembling diligence. Overhead crane, moveable crane, loom crane, variable crane, framework crane, knock over the crane, jib crane is a portion of the frequently consumed cranes. The inquiry of [1] Plant development Promoting achieve of Seaweeds unruffled from East Coast of Tamil Nadu. A crane snare is a doohickey consumed for in receipt of and lifting up the masses by ways for a crane. It is necessarily a raising fixing anticipated representing in a disc or relation of a bracing sequence or the fastening of a constrain or linking affection. From this study, [2] Enhancement of fuel utilization and productivity of the vehicles is explained. Crane snares with trapezoidal, around and triangular fractious area are normally consumed. Next, to these lines, it should be outlined and twisted to put into words the majority excessive execution without discontent. Along these lines, the point of this searching is to study elongate cheating design indoors a crane snare of diverse cross areas consuming regular, mathematical and tentative approaches. Residual stress analysis in austenitic stainless steel weldment by finite element method is discussed in [7]. Evaluation of mechanical properties of aluminium metal matrix composite for marine applications is discussed in [8]. Experimental investigation of tensile and impact behaviour of aluminium metal matrix composite for the turbocharger is discussed in [9]. Controllability of second-order impulsive neutral functional integro differential inclusions with an infinite delay is discussed in [10].

\section{MODELING}

3D displaying is the way toward making a 3D portrayal of any surface or question by controlling 
polygons, edges, and vertices in reproduced 3D space. 3D displaying can be accomplished physically with specific 3D generation programming that gives a craftsman a chance to make and misshape polygonal surfaces, or by checking true protests into an arrangement of information indicates that can be utilized speak to the question carefully. Solid Works is a strong displaying PC supported outline (CAD) and PC helped building (CAE) PC program that keeps running on Microsoft Windows. Solid Works is distributed by Dassault Systems.

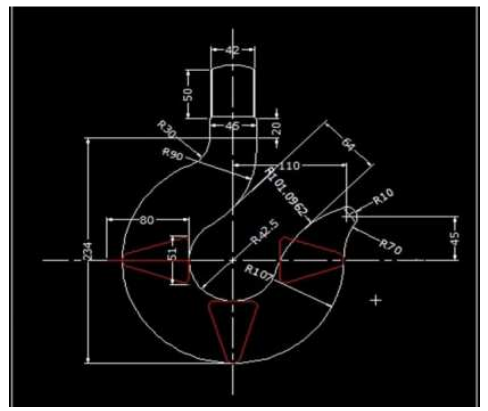

Figure 1: Modeling in Auto-CAD

The above figure 1 shows the $2 \mathrm{D}$ view of the crane created by the AutoCAD software. The all dimensions of the crane is taken from the presently used crane in the industries. The designed crane hook is created in the auto cad software for drafting. In the design ISO standards are only used.

\section{Solid Modeling}

Solid modeling (or modelling) is a consistent set of principles for mathematical and computer modeling of threedimensional solids. Solid modeling is distinguished from related areas of geometric modeling and computer graphics by its emphasis on physical fidelity. ${ }^{[1]}$ Together, the principles of geometric and solid modeling form the foundation of computeraided design and in general support the creation, exchange, visualization, animation, interrogation, and annotation of digital models of physical objects.

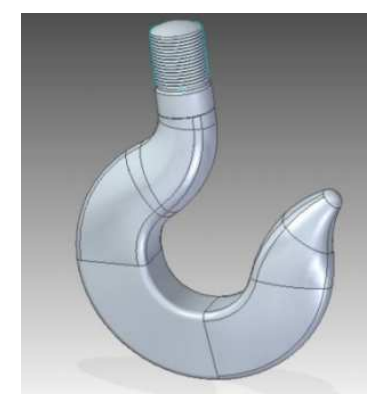

Figure 2: Modeling of Crane Hook in Ansys

\section{Meshing}

Mesh generation is the practice of generating a polygonal or polyhedral mesh that approximates a geometric domain. The term "grid generation" is often used interchangeably. Typical uses are for rendering to a computer screen or for physical simulation such as finite element analysis or computational fluid dynamics. 


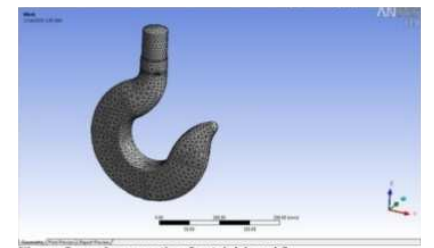

Figure 3: Meshing of Crane Hook in Ansys

\section{Stress Analysis on Materials for Wrought Iron}

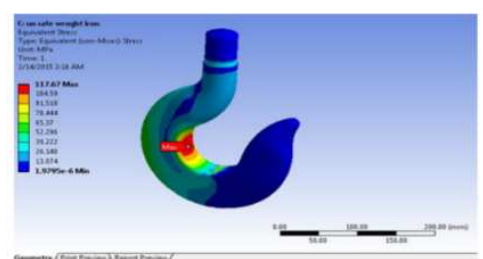

Figure 4: Stress Analysis on Crane Hook with Wrought Iron Material

The above figure shows the result of the crane hook by using the ANSYS workbench software. The stress of the crane hook measured in simulation. In the figure 4 the multi colors of rectangle is showed. The colors are denoting the safe and unsafe level of the iron crane hook. The blue color in the rectangle is maximum point and the red color of the rectangle is maximum point.

\section{For aluminum alloy}

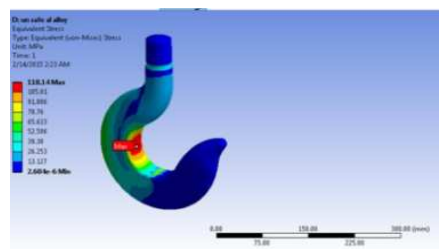

Figure 5: Stress Analysis on Crane Hook with Aluminum Alloy Material

The above figure shows the result of the crane hook by using the ANSYS workbench software. The stress of the crane hook measured in simulation. In the figure 5 the multi colors of rectangle is showed. The colors are denoting the safe and unsafe level of the aluminum crane hook. The blue color in the rectangle is maximum point and the red color of the rectangle is maximum point.

\section{For forged steel}

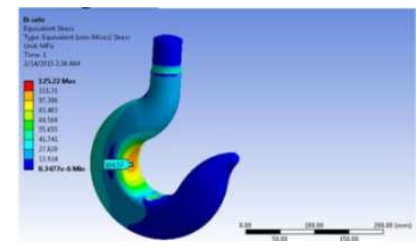

Figure 6: Stress Analysis on Crane Hook with Forged Steel Material

The above figure shows the result of the crane hook by using the ANSYS workbench software. The stress of the crane hook measured in simulation. In the figure 6 the multi colors of rectangle is showed. The colors are denoting the safe and unsafe level of the froged crane hook. The blue color in the rectangle is maximum point and the red color of the rectangle is maximum point. 


\section{RESULT AND CONCLUSIONS}

The crane hook was successfully designed as the dimensions by using SOLIDWORKS software. And the 3D model of the crane hook is analyzed by the ANSYS software. The material outcomes are given in the underneath arrangement. The consequences of stress investigation ascertained from FEA examination for different diverse material, for example, Forged Steel, Wrougt iorn/MS, Allmuniun Alloy. For the diverse Material, It is watched that keeping the tone are same with various Material topology we will get distinctive outcomes, yet from the above table. it is discovered that the Forged Steel Material gives least anxiety which portray in beneath table.

Table 1: Comparison of Stress Analysis on Crane Hook made of Different Materials

\begin{tabular}{|l|c|c|}
\hline $\begin{array}{c}\text { Name of the } \\
\text { Material }\end{array}$ & $\begin{array}{c}\text { Stress } \\
\text { N/mm2 }\end{array}$ & $\begin{array}{c}\text { Max. Equivalent } \\
\text { Stress N/mm2 }\end{array}$ \\
\hline FS & 99.66 & 105.34 \\
\hline Iron & 126.4 & 118.97 \\
\hline Aluminum alloy & 129.1 & 119.29 \\
\hline
\end{tabular}

\section{REFERENCES}

1. Muthezhilan, R et al., (2014). Plant Growth Promoting Effect of Seaweeds Collected from East Coast of Tamil Nadu, India.

2. Elavarasi et al., (2017) Enhancement of fuel consumption and efficiency of the vehicles, International Journal of Mechanical Engineering and Technology, 8(4), pp. 456-460.

3. Griffiths, E. E et al., (1986). Remote controlled crane hook coupler. U. S. Patent 4,573,725.

4. Campbell, D. B et al., (1966). Weight sensing crane hook. U. S. Patent 3,290,931.

5. Boyd, W. E et al., (1950). Crane hook. U. S. Patent 2,514,307.

6. Rashmi, U., (2011). Stress analysis of crane hook and validation by photo-elasticity. Engineering, 2011.

7. Jayakumar, $N$ et al., (2016) Residual stress analysis in austenitic stainless steel weldment by finite element method. Indian Journal of Science and Technology, vol. 8, no. 36.

8. Ch. Venkata Rajam, P. V. K. Murthy \& M. V. S. Murali Krishna, Linear Static Structural Analysis of Optimized Piston for BioFuel Using ANSYS, International Journal of Mechanical and Production Engineering Research and Development (IJMPERD), Volume 3, Issue 2, May - June 2013, pp. 11-20

9. Venugopal, A et al., (2015) Evaluation of mechanical properties aluminium metal matrix composite for marine applications, ARPN Journal of Engineering and Applied Sciences, vol. 10, no. 13, pp. 5557-5559, 2015.

10. Mohan, T et al., (2015) Experimental investigation of tensile and impact behaviour of aluminium metal matrix composite for the turbocharger, ARPN Journal of Engineering and Applied Sciences, vol. 10, no. 13, pp. 5672-5674.

11. Subramaniyan et al., (2015) Controllability of second-order impulsive neutral functional integrodifferential inclusions with an infinite delay, Advances and Applications in Fluid Mechanics, vol. 18, no. 1, pp. 1-30.

12. Madhusudhanan et al., (2009). High performance designs for linear algebra operations on image processing. International Journal of MC Square Scientific Research, 1 . 